\title{
Executive Function Disorder
}

National Cancer Institute

\section{Source}

National Cancer Institute. Executive Function Disorder. NCI Thesaurus. Code C160587.

Cognitive, emotional, and behavioral difficulties that often occur in conjunction with frontal lobe disorders, including traumatic injury and dementia. It is also a feature of attention deficit disorder and other non-trauma-induced conditions. 